medRxiv preprint doi: https://doi.org/10.1101/2021.10.23.21265391; this version posted October 26, 2021. The copyright holder for this preprint (which was not certified by peer review) is the author/funder, who has granted medRxiv a license to display the preprint in perpetuity.

It is made available under a CC-BY-NC-ND 4.0 International license .

\title{
Sex Modifies the Effect of Genetic Risk Scores for Polycystic Ovary Syndrome on Metabolic Phenotypes
}

\author{
Ky'Era V. Actkins ${ }^{1,2}$, Genevieve Jean-Pierre ${ }^{2,3}$, Melinda C. Aldrich ${ }^{3,4,5}$, Digna R. Velez \\ Edwards $^{5,6,7}$, and Lea K. Davis ${ }^{2,3}$
}

1. Department of Microbiology, Immunology, and Physiology, Meharry Medical College, Nashville, TN

2. Vanderbilt Genetics Institute, Vanderbilt University Medical Center, Nashville, TN

3. Division of Genetic Medicine, Department of Medicine, Vanderbilt University Medical Center, Nashville, TN

4. Department of Thoracic Surgery, Vanderbilt University Medical Center, Nashville, TN

5. Department of Biomedical Informatics, Vanderbilt University Medical Center, Nashville, TN

6. Vanderbilt Epidemiology Center, Institute of Medicine and Public Health, Vanderbilt University Medical Center, Nashville, TN

7. Division of Quantitative Sciences, Department of Obstetrics and Gynecology, Vanderbilt University Medical Center, Nashville, TN

Short title: Genetic sex effects of polycystic ovary syndrome

\section{Co-Corresponding authors}

Lea Davis

Associate Professor of Medicine

Vanderbilt Genetics Institute

Division of Genetic Medicine

Department of Medicine

511-A Light Hall

Vanderbilt University

2215 Garland Ave

Nashville, TN 37232

Office Tel: $615-875-9478$

Ky'Era Actkins

PhD Candidate

Meharry Medical College

1005 Dr. DB Todd Blvd

Nashville, TN 37208

Keywords: polycystic ovary syndrome, sex differences, polygenic risk scores, phenome-wide association study, electronic health records, mediation analysis

Funding/Support: KVA is funded by F31HD103397. LKD is funded by U54MD010722. MCA is funded by a grant from $\mathrm{NIH} / \mathrm{NCl}$ (U01CA253560). Datasets were obtained using the Vanderbilt 
45 University Advanced Computing Center for Research and Education. This resource is funded by 46 institutional, private, and federal grants, which include NIH funded Shared Instrumentation Grant

47 S10OD017985 and S10RR025141 and CTSA grants UL1TR002243, UL1TR000445, and

48 UL1RR024975.

Author contributions: LKD and KVA designed the study. KVA performed the statistical analyses. All authors contributed to the interpretation of the results, the revision of the manuscript, and approved the final manuscript.

Competing interests: The authors declare they have no competing interests.

Data availability statement: All GWAS summary statistics used in this study are publicly available and can be obtained from the following consortium groups and websites: International PCOS Consortium (https://doi.org/10.17863/CAM.27720), UK Biobank (http://www.nealelab.is/uk-biobank), HERMES (http://www.broadcvdi.org/), and CARDIoGRAMplusC4D (http://www.cardiogramplusc4d.org/). The summary statistics used from the Million Veteran Project can be accessed through dbGaP under accession number phs001672.v6.p1. The electronic health record data that support the findings of this study are available from Vanderbilt University Medical Center, but restrictions apply to the availability of these data, which were used under license for the current study, and so are not publicly available. Data are, however, available from the authors upon reasonable request and with permission of Vanderbilt University Medical Center. 
medRxiv preprint doi: https://doi.org/10.1101/2021.10.23.21265391; this version posted October 26, 2021. The copyright holder for this preprint (which was not certified by peer review) is the author/funder, who has granted medRxiv a license to display the preprint in perpetuity.

It is made available under a CC-BY-NC-ND 4.0 International license .

\section{Abstract}

68 Females with polycystic ovary syndrome (PCOS), the most common endocrine disorder in women, have an increased risk of developing metabolic disorders such as insulin resistance, obesity, and type 2 diabetes (T2D). Furthermore, while only diagnosable in females, males with

71 a family history of PCOS can also exhibit a poor cardiometabolic profile. Therefore, we aimed to elucidate the role of sex in the relationship between PCOS and its comorbidities by conducting bidirectional genetic risk score analyses in both sexes. We conducted a phenome-wide association study (PheWAS) using PCOS polygenic risk scores (PCOS PRS) to understand the pleiotropic effects of PCOS genetic liability across 1,380 medical conditions in females and males recorded in the Vanderbilt University Medical Center electronic health record (EHR) database. After adjusting for age and genetic ancestry, we found that European descent males with higher $\mathrm{PCOS}_{\mathrm{PRS}}$ were significantly more likely to develop cardiovascular diseases than females at the same level of genetic risk, while females had a higher odds of developing T2D. Based on observed significant associations, we tested the relationship between PRS for comorbid conditions (e.g., T2D, body mass index, hypertension, etc.) and found that only PRS generated for BMI and T2D were associated with a PCOS diagnosis. We then further decomposed the T2D PRS association with PCOS by adjusting the model for measured BMI and $\mathrm{BMI}_{\text {residual }}$ (enriched for the environmental contribution to $\mathrm{BMI}$ ). Results demonstrated that genetically regulated BMI primarily accounted for the relationship between T2D $\mathrm{PRS}$ and PCOS.

This was further supported in a mediation analysis, which only revealed clinical BMI measurements, but not $\mathrm{BMI}_{\text {residual, }}$ as a strong mediator for both sexes. Overall, our findings show that the genetic architecture of PCOS has distinct metabolic sex differences, but these associations are only apparent when PCOSPRS is explicitly modeled. It is possible that these pathways are less explained by the direct genetic risk of metabolic traits than they are by the 91 risk factors shared between them, which can be influenced by biological variables such as sex. 
medRxiv preprint doi: https://doi.org/10.1101/2021.10.23.21265391; this version posted October 26, 2021. The copyright holder for this preprint (which was not certified by peer review) is the author/funder, who has granted medRxiv a license to display the preprint in perpetuity.

It is made available under a CC-BY-NC-ND 4.0 International license .

\section{Introduction}

Polycystic ovary syndrome (PCOS) is a highly heritable endocrine disorder that affects $5 \%-21 \%$ of females of reproductive age who are typically diagnosed by having two or more of the following features under the Rotterdam criteria: polycystic ovaries, oligo- and anovulation, or hyperandrogenism [1-3]. Although Rotterdam is the most common PCOS criteria, other criteria can be used for diagnosis, including the National Institutes of Health criteria, the Androgen Excess and PCOS Criteria, or the 2018 International Evidence Based PCOS guidelines [2]. Each criterion slightly differs in requirements in an effort to cover the range of PCOS symptoms that are exhibited in patients. However, as a result of the differing diagnostic criteria, the heterogenous presentation of symptoms, and the prevalent comorbidities that reside outside of diagnostic requirements patients often spend years seeking a diagnosis or worse, may be one of the $75 \%$ of females estimated to be undiagnosed $[4,5]$.

Many clinicians select criteria based on their perception of the most defining PCOS feature [6]. In some cases, as with the Androgen Excess and PCOS Society criteria [7], this will mean hyperandrogenism, a symptom that typically manifests as acne, hirsutism, or alopecia [8]. Androgen excess is also hypothesized to underlie many of the comorbid metabolic dysfunctions experienced by patients such as insulin resistance, obesity, metabolic syndrome, type 2 diabetes, and cardiovascular diseases (CVD). However, as previous studies have shown, the genetic risk factors present in patients with metabolic manifestations of PCOS could differ from others who have primary presentations of reproductive dysfunction $[9,10]$. PCOS is multifactorial and twin studies estimate heritability at $70 \%$ [11-14]. With an underlying polygenic architecture, multiple variants are hypothesized to be involved in the development of PCOS $[15,16]$. Furthermore, the variation of clinical features can be partially explained by ancestry informative markers, indicating potential population specific effects $[17,18]$. Rare variants in genes, such as $D E N N D 1 A$, have also been identified in family studies for PCOS alongside many other genetic variants identified from GWAS [19]. Despite the small 
effect size of individual common variants, aggregation of common risk variants together as a polygenic (or genetic) risk score (PRS) reflects the overall additive genetic liability to PCOS in individuals. This marker of disease risk is associated with PCOS diagnosis in multiple ancestries and offers many advantages to parsing out the genetic etiology of PCOS that is entangled with

123 its comorbid presentations [11-13]. Furthermore, there is increasing evidence that a spectrum 124 of clinical PCOS manifestations for PCOS is also correlated with the PRS for PCOS [11]. pleiotropic associations with other health conditions in a hospital biobank population through a phenome-wide association study (PheWAS). By using a genetic model, we were able to determine sex-differentiated effects associated with PCOS genetic risk, revealing the impact of PCOS-associated inherited genetic variation in males, despite the fact that PCOS is only diagnosed in females. We further implemented several analyses to determine the mediating role of body mass index (BMI) on cardiometabolic comorbidities, and further identified the directionality of their effects through causal mediation analyses.

\section{Methods}

\section{VUMC EHR-linked Biorepository}

139 Tennessee, with several outpatient clinics throughout Tennessee and the surrounding states 140 offering primary and secondary care. Medical records have been electronically documented at

141 VUMC since the early 1990s, resulting in a clinical research database of over 3 million EHRs 142 referred to as the Synthetic Derivative [20]. EHRs include demographic information, health 143 information documented through International Classification of Disease, Ninth Revision (ICD9) 144 and Tenth Revision (ICD10) codes, procedural codes (CPT), clinical notes, medications, and 145 laboratory values. This information is linked with a DNA biorepository known as BioVU. Use of 
146 EHRs and genetic data for this study was approved by the Vanderbilt University Institutional

147 Review Board (IRB \#160279).

148

149

150

Genetic data

BioVU contains 94,474 individuals genotyped on the MEGA ${ }^{\mathrm{EX}}$ platform [21]. The QC pipeline removed SNPs with low genotyping call rate $(<0.98)$ and individual subjects who were related (pi-hat $>0.2$ ), had low call rates $(<0.98)$, sex discrepancies, and excessive heterozygosity (Fhet $>0.2)$. A principal component $(\mathrm{PC})$ analysis (PCA) was performed on remaining individuals to determine genetic ancestry using FlashPCA2 [22]. BioVU genotyped samples were stratified by ancestral origin based on PCs herein referred to as the European (EUR) descent or African (AFR) descent dataset. Extended details for the quality control of these datasets have been described previously [23].

\section{Publicly available summary statistics}

Genome-wide association study (GWAS) summary statistics were acquired for PCOS, BMI, diastolic blood pressure, systolic blood pressure, pulse, type 2 diabetes, heart failure, and coronary artery disease (i.e., all of the significant phenotypic associations observed in the PheWAS models) to further establish the strength of associations between PCOS and its comorbidities through subsequent analyses. Each GWAS was selected based on public availability, sample size, and sample diversity.

The Genetic Investigation of ANthropometric Traits (GIANT) consortium body mass index (BMI) summary statistics included 339,224 individuals of European and non-European descent from over 125 studies. These BMI summary statistics were used as a proxy for obesity summary statistics [24]. Blood pressure traits (diastolic, systolic, and pulse) and type 2 diabetes (T2D) summary statistics were obtained from the Million Veterans Program (MVP), a large biobank consortium effort that houses biobank data from various sites in the Department of 
173 Veterans Affairs health system [25]. Blood pressure traits were generated from a trans-ethnic

174 sample of over 750,000 individuals from MVP [26]. T2D summary statistics were generated from

175 a meta-analysis using data from 1.4 million participants in various biobanks and consortia

176 groups [27]. Heart failure summary statistics were collected from 47,309 cases and 930,014

177 controls of European ancestry across nine studies in the Heart Failure Molecular Epidemiology

178 for Therapeutic Targets (HERMES) consortium as a proxy for heart disease [28]. Finally,

179 coronary artery disease (CAD) datasets generated from the Coronary Artery Disease Genome-

180 wide Replication and Meta-analysis plus The Coronary Artery Disease (CARDloGRAMplusC4D)

181 consortium were used as the genetic measurement for the coronary atherosclerosis phenotype

182 [29]. This meta-analysis assembled 60,801 cases and 123,504 controls of multiple ancestries

183 across forty-eight study sites.

184

185

186

187

188

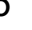

\section{Statistical analysis}

\section{Generation of polygenic risk scores (PRS)}

PCOSPRS were calculated with PRS-CS software using the weighted sums of the risk allele effects as reported in the summary statistics from the Day et al. GWAS of PCOS and applying a Bayesian continuous shrinkage parameter select SNP features and to model linkage disequilibrium $[16,30]$. The details of these methods have been previously described elsewhere

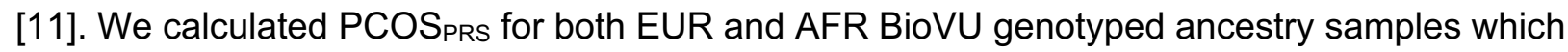
were previously shown to be associated with a PCOS diagnosis defined by a coded strict PCOS definition in our previously published EHR-based algorithm [11].

Phenome-wide association study (PheWAS)

Next, we were interested in identifying the pleiotropic effects of the genetic susceptibility to PCOS on the medical phenome. Therefore, in a PheWAS framework we analyzed the effects of PCOS $\mathrm{PRS}$ across 1,380 medical conditions. This analysis was first performed in a female 
201 sample for our EUR and AFR ancestry datasets to validate the PRS and identify potential

202 pleiotropic relationships (Supplementary Figures 1-5). Although males cannot be diagnosed

203 with PCOS, they still harbor genetic risk for PCOS. Thus, we extended the analysis to males to

204 examine sex differences. Finally, we performed a sex-combined PheWAS to increase statistical

205 power. In the sex-combined logistic regression model, covariates included median age of

206 individuals medical record, sex, and the first ten principal components. In the sex-stratified

207 models, covariates included median age and the first ten PCs.

Interaction analysis

For each phenotype with evidence of a significant main effect of PCOS $\mathrm{PRS}_{\text {in }}$ ither sex,

211 we tested for two-way interactions (sex * PCOS ${ }_{P R S}$ ) to determine which of the significant sex

212 stratified PheWAS associations were influenced by biological effects of sex. Selected

213 phenotypes of interest that met the phenome-wide false discovery rate $(q<0.05)$ were tested

214 for interactions $(N=10)$. For these interaction analyses, sex-combined models included the

215 main effects of PCOS $\mathrm{PRS}$, median age of individuals medical record, sex, and the top ten PCs.

Several sensitivity analyses were performed to assess the robustness of the significant

219 phenome-wide findings. First, BMI is strongly correlated with both PCOS and its comorbidities,

220 and thus, can influence the strength of the results [31]. Therefore, we adjusted each model for

221 BMI (median measurement across an individual's EHR) to observe whether the significant

222 phenotypes associated with PCOS ${ }_{\text {PRS }}$ were independent of obesity-related effects. In addition to

223 adjusting for BMI, the model was adjusted for median age, sex (only in the sex-combined

224 sample), and the top ten PCs.

Next, we evaluated which phenotypes were dependent on a PCOS diagnosis in females 
227 associations and provided insight into which phenotypes were exclusively correlated with

228 genetic risk, even in the absence of PCOS.

Finally, given that BMI has strong contributions from both genetic and environmental sources of variance, we revisited the previous PheWAS analyses to specifically account for the

231 environmental contribution of BMI. To do this, we calculated the residuals of median BMI adjusted for $\mathrm{BMI}_{\mathrm{PRS}}\left(\right.$ residuals(medianBMI $\left.\sim \mathrm{BM} \mathrm{IRS}_{\mathrm{PR}}\right)$ ), herein referred to as $\mathrm{BMI}_{\text {residual. }} \mathrm{BMI}_{\text {residual }}$ were then used in a subsequent sensitivity analysis of the previously described PheWAS.

\section{Genetic correlation}

Linkage Disequilibrium Score Regression (LDSC) was used to calculate genetic reference population. The European reference panel was used for all analyses based on the demographic majority of each of the GWAS samples. phenotypes identified in the PheWAS. PRS were then used as the independent variable in a

247 logistic regression model against PCOS diagnosis as the dependent variable. BioVU genotyped 248 datasets were filtered to females and contained 361 PCOS cases and 29,035 controls in the

249 EUR dataset and 189 PCOS cases and 9,229 controls in the AFR dataset. Selection of PCOS 250 cases and controls have been described elsewhere [11]. In brief, cases required PCOS billing 251 codes and no exclusion codes. Controls excluded individuals who had any inclusion or exclusion codes [11]. All models were adjusted for median age of the individuals medical record, 
253 and the top ten PCs for each ancestry. Median BMI was included as a covariate in the

254 sensitivity analysis.

255 Lastly, we adjusted for BMI residual in the logistic regression models in place of BMI. Next,

256 we performed a sensitivity analysis to test the effect of $B M I_{\text {residual }}$ and $B M I_{\text {PRS }}$ separately on

257 PCOS diagnosis. A multiple testing correction of $p<7.35 e-04(0.05 / 68)$ was implemented to

258 account for all statistical tests. All statistical analyses were done using R 3.6.0.

\section{Mediation analysis}

To test whether $\mathrm{BMI}$ or $\mathrm{BMI}_{\text {residual }}$ mediates the pleiotropic relationships between PCOS and associated cardiometabolic conditions, a mediation analysis was employed using the mediation R package for both AFR and EUR genotyped samples [33]. For the first set of mediation analyses, we modeled $\mathrm{BMI}_{\mathrm{PRS}}$ and $\mathrm{BMI}_{\text {residual }}$ as exposures, $\mathrm{T} 2 \mathrm{D}$ diagnosis as the mediator, and PCOS case status as the outcome. Another reciprocal model was tested with the same exposures, but with PCOS diagnosis as the mediator and T2D as the outcome. This analysis tested the hypothesis that the risk conferred by BMI on one phenotype (e.g., PCOS) in turn increases risk for another other phenotype (e.g., T2D). We restricted this analysis to the female population. All models were further adjusted for median age and the top ten PCs. In our second set of mediation analyses, we tested whether genetic risk for PCOS or

$271 \mathrm{~T} 2 \mathrm{D}$ also influenced $\mathrm{BMI}_{\text {residual }}$ through the manifestation of either clinical condition. For example, 272 we modeled PCOSPRS as the exposure variable, T2D diagnosis as the mediator and BMI residual 273 as the outcome. Finally, in a female only analysis, T2DPRS was modeled the exposure variable,

274 PCOS diagnosis was included as the mediator, and $\mathrm{BMI}_{\text {residual }}$ again was modeled as the 275 outcome.

$276 \quad$ Finally, for our last set of mediation analyses, we examined the mediating effect of both 277 measured $\mathrm{BMI}$ and $\mathrm{BMI}_{\text {residual }}$ on the relationship between $\mathrm{PCOS}_{\mathrm{PRS}}$ (exposure) and the diagnosis of hypertension and hypertensive heart disease (i.e., outcomes that demonstrated 
evidence of significant interactions with sex). T2D was also tested because it was significantly associated with PCOS $\mathrm{PRS}$ in both sexes. PCOS $\mathrm{PRS}$ was modeled as the exposure variable and T2D $($ phecode $=270.2)$ hypertension $($ phecode $=411)$, and hypertensive heart disease (phecode $=401.21)$ were modeled as the outcome variables. Models were considered significant when the average direct effect (ADE) and average causal mediation effect (ACME) both passed $p<7.35 e-04$. All mediation analyses were performed with 1,000 bootstrap simulations to estimate the confidence intervals and determine an empirical $p$-value.

\section{Results}

\section{PCOS PRS $_{\text {PheWAS results }}$}

The PCOS PRS PheWAS was applied to 66,903 EUR individuals from BioVU. When

restricted to females $(N=37,240)$, two phenotypes were significantly associated with PCOSPRS

$($ Bonferroni corrected $p$-value $=4.56 \mathrm{e}-05)($ Figure $1 \mathrm{a}): \mathrm{T} 2 \mathrm{D}($ odds ratio $[\mathrm{OR}]=1.10,95 \%$

confidence interval $[\mathrm{Cl}]=1.06-1.14, \mathrm{p}=5.54 \mathrm{e}-07)$ and diabetes mellitus $(\mathrm{OR}=1.09,95 \% \mathrm{Cl}=$

$1.05-1.13, p=2.20 \mathrm{e}-06)$. When the analysis was restricted to males $(\mathrm{N}=29,663$; Figure $1 \mathrm{~b})$,

hypertensive heart disease was significant $(\mathrm{OR}=1.15,95 \% \mathrm{Cl}=1.08-1.23, \mathrm{p}=2.07 \mathrm{e}-05)$

alongside a cluster of nominally $(p<0.05)$ associated cardiovascular phenotypes with similar

effect sizes $(O R=1.06$ to 1.08$)$. This included hypertension $(O R=1.06,95 \% \mathrm{Cl}=1.03-1.10$,

$p=1.30 e-04)$, essential hypertension $(O R=1.06,95 \% \mathrm{Cl}=1.03-1.10, p=2.49 e-04)$, and

coronary atherosclerosis $(O R=1.06,95 \% \mathrm{Cl}=1.02-1.10, p=1.40 e-03) . T 2 D(O R=1.07,95 \% \mathrm{Cl}$

$=1.03-1.11, p=7.04 \mathrm{e}-04)$ and several other endocrine phenotypes were also modestly associated with PCOS PRs in males.

In the EUR sex-combined model, four phenotypes were significantly associated with 
$p=1.03 e-08)$. Following was obesity $(\mathrm{OR}=1.07,95 \% \mathrm{Cl}=1.04-1.11, \mathrm{p}=9.68 \mathrm{e}-06)$ and

$$
\text { hypertensive heart disease }(\mathrm{OR}=1.11,95 \% \mathrm{Cl}=1.06-1.16, \mathrm{p}=3.57 \mathrm{e}-05) \text {. Three }
$$

307 cardiovascular diseases were also nominally associated with PCOS $\mathrm{PRS}$, presumably due to the

308 addition of males. PCOS PRs yielded an OR of $1.21(95 \% \mathrm{Cl}=1.08-1.36, \mathrm{p}=7.82 \mathrm{e}-04)$ for an

309 association with polycystic ovaries, falling just short of phenome-wide significance.

No associations passed Bonferroni correction in the AFR ancestry analysis, which

included a total of 12,383 individuals (Supplementary Figure 1).

Interaction analysis

The sex interaction analysis demonstrated that males with a high PCOS $\mathrm{PRS}_{\text {were }}$

$\left.=1.03-1.10, p=1.30 \mathrm{e}-04 ; \mathrm{OR}_{\text {Females }}=1.03,95 \% \mathrm{Cl}=1.00-1.06, \mathrm{p}=0.07\right)$, essential

hypertension (interaction $p=7.71 \mathrm{e}-03, \mathrm{OR}_{\text {Males }}=1.06,95 \% \mathrm{Cl}=1.03-1.10, \mathrm{p}=2.49 \mathrm{e}-04$;

$\mathrm{OR}_{\text {Females }}=1.03,95 \% \mathrm{Cl}=1.00-1.06, \mathrm{p}=0.08$ ), and hypertensive heart disease (interaction

$p=0.01, \mathrm{OR}_{\text {Males }}=1.15,95 \% \mathrm{Cl}=1.08-1.23, \mathrm{p}=2.07 \mathrm{e}-05 ; \mathrm{OR}_{\text {Females }}=1.05,95 \% \mathrm{Cl}=0.98-1.13$

$p=0.16)$ than females with the same PCOS

observed when calculating the prevalence for each trait by decile of $\mathrm{PCOS}_{\mathrm{PRS}}$, which only

$$
\text { showed an upwards trend across deciles for traits with a significant sex effect (Figure 3). }
$$

Together, these results showed that sex is an important modifier of PCOS genetic risk.

Sensitivity analyses adjusting for BMI and PCOS case status

In our first set of PheWAS sensitivity analyses for the EUR population, we adjusted for median BMI in all of the PRS-PheWAS models. There were no surviving associations in the 328 sex-combined model or stratified analyses, suggesting BMI may mediate the pleiotropic effects 
331 demonstrated a significant positive phenome-wide association with T2D and diabetes mellitus

332 (Supplementary Figure 2b).

Genetic correlation results

We found that BMI $\left(r_{g}=43.32 \%, p=8.77 e-19\right)$ and T2D $\left(r_{g}=29.26 \%, p=3.25 e-09\right)$ had

the strongest genetic correlation with PCOS (Table 2). Heart failure $\left(r_{g}=26.51 \%, p=0.0025\right)$

and pulse pressure $\left(r_{g}=13.46 \%, p=0.011\right)$ were also modestly significantly with PCOS. CAD

bordered the significance threshold, but systolic and diastolic blood pressure were not significantly genetically correlated with PCOS.

Cardiometabolic PRS Analysis of PCOS diagnosis

Outside of T2D and BMI, none of the PRS built for CAD, heart failure, or blood pressure

were significantly associated with a PCOS diagnosis in females of either EUR or AFR descent

344 (Figure 4).

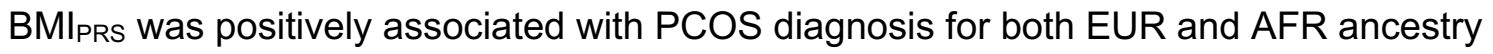
populations $\left(p_{E U R}=3.71 e-08, p_{A F R}=0.02\right)$, but not independently of clinically measured BMI values. T2D $D_{\text {PRS }}$ in the EUR dataset yielded similar results with PCOS diagnosis, again losing significance upon addition of a BMI covariate in the model $\left(\mathrm{OR}_{\text {unadjusted }}=1.16,95 \% \mathrm{Cl}=1.04\right.$ $\left.1.30, p=0.007 ; \mathrm{OR}_{\text {adjusted }}=1.09,95 \% \mathrm{Cl}=0.97-1.22, \mathrm{p}=0.16\right)$. To determine whether this reduction in effect size was due to the genetic correlation between T2D and BMI, we also tested

351 a model in which $\mathrm{T}_{2} \mathrm{D}_{\text {PRS }}$ was adjusted for $\mathrm{BMI}_{\text {residual }}$ (i.e., variance remaining in $\mathrm{BMI}$ after

352 removing variance due to BMI PRS) instead of BMI. This model indeed recovered the original

353 association between T2D PRS $\left(\mathrm{OR}_{\mathrm{EUR}}=1.18,95 \% \mathrm{Cl}=1.05-1.32, \mathrm{p}_{\mathrm{EUR}}=0.005\right)$ and PCOS

354 diagnosis for the EUR population, suggesting that genetically predicted BMI mediates the association between T2D PRs and PCOS diagnosis (Figure 5). 
Mediation analysis in females with BMI as an exposure variable

To further quantify the degree to which BMI influenced the shared genetic pathways

between PCOS and T2D, a mediation analysis was performed with $\mathrm{BMI}_{\mathrm{PRS}}$ and $\mathrm{BMI}_{\text {residual }}$ as the exposure variables, PCOS diagnosis as the outcome variable, and T2D as the mediator. The reciprocal model was then tested with T2D diagnosis as the outcome and PCOS as the mediator (Table 3). We found that both phenotypes acted as significant mediators when BMlPRS and $\mathrm{BMI}_{\text {residual }}$ were exposure variables. PCOS diagnosis had a stronger mediating effect on T2D when $\mathrm{BMI}_{\text {residual }}$ was the exposure variable compared to $\mathrm{BMI}$ PRS $(13.6 \%$ vs $7.1 \%)$. However, the opposite was true for $\mathrm{T} 2 \mathrm{D}$, which mediated more of risk conferred by $\mathrm{BMI}_{\mathrm{PRS}}$ than $\mathrm{BMI}_{\text {residual }}$ on the PCOS outcome ( $9 \%$ vs $2.1 \%)$.

PheWAS sensitivity analysis with $B M I_{\text {residual }}$

We revisited the PheWAS analysis in light of the findings for BMI residual. By covarying for

$\mathrm{BMI}_{\text {residual, }}$ (e.g., environmental estimate of BMI), we observed almost no difference from the

371 original results in our female sample (Supplementary Figure 4a). T2D remained significant in

372 females $(\mathrm{OR}=1.10,95 \% \mathrm{Cl}=1.06-1.15, \mathrm{p}=1.69 \mathrm{e}-06)$, as did diabetes mellitus $(\mathrm{OR}=1.09$,

$37395 \% \mathrm{Cl}=1.05-1.13, \mathrm{p}=9.91 \mathrm{e}-06)$. These associations also appeared in the combined dataset

374 alongside obesity (Supplementary Figure 5). Although none of the phenotypes passed

375 Bonferroni correction for males, many of the associations improved in estimate effects

\section{6 (Supplementary Figure 4b).}

Mediation analysis in the sex-combined and sex-stratified samples 
383 Here we observed a modest association that showed PCOS diagnosis mediated $33 \%$ of the risk

384 conferred by T2D PRS on BMI residual whereas T2D diagnosis did not explain any of the variance in

$385 \quad \mathrm{BMI}_{\text {residual }}$ due to PCOS PRS (Table 4).

386 Lastly, the effects of BMI on PCOS comorbidities T2D, hypertension, and hypertensive

387 heart disease were explored (Table 5). We found that $\mathrm{BMI}_{\text {residual }}$ was not a significant mediator

388 for any of the tested models, even though clinical BMI was a significant mediator for T2D in

389 females and a significant mediator for hypertensive heart disease in males. This again

390 implicated genetically regulated $\mathrm{BMI}$ as the main source of the mediating effect for males since

391 median BMI significantly mediated $14.8 \%$ of the variance in hypertensive heart disease $(p=$

$392<2 e-16)$ and mediated $23.7 \%$ of the variance in hypertension $(p=0.002)$ due to PCOS PRS. The

393 lack of an association with $\mathrm{BMI}_{\text {resiudal }}$ in females also suggests genetically regulated BMI as the

394 primary mediator for T2D, where it mediated $31.5 \%$ of the variance explained by the PCOS PRS.

395

396

397

\section{Discussion}

Through a comprehensive analysis of PCOS genetic risk across multiple phenotypes, we identified sex differences in the cardiometabolic traits associated with PCOS genetic risk. Among these, the most notable difference was that males with high PCOS PRs $_{\text {were }}$ at greater risk of cardiovascular conditions than females at the same level of genetic risk. Genetically predicted BMI was revealed as a primary mediator of this risk in males, whereas both environmental and genetic BMI variance components mediated risk of T2D conferred by

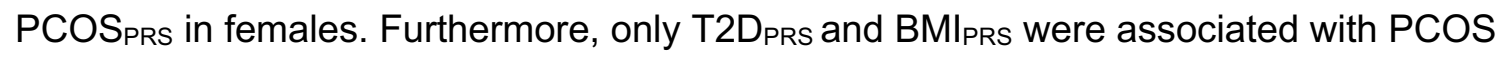
diagnosis, indicating that many of the associations observed in the PCOS PRS $_{\text {PheWAS were }}$ primarily driven by PCOS genetic risk and not the genetic effects of the identified comorbidities. There is growing interest in studying PCOS related effects in males whether through their relationship to first-degree family members with PCOS or by an equivalent phenotype [3436]. Generally, males with mothers or sisters with PCOS tend to exhibit a poorer 
medRxiv preprint doi: https://doi.org/10.1101/2021.10.23.21265391; this version posted October 26, 2021. The copyright holder for this preprint (which was not certified by peer review) is the author/funder, who has granted medRxiv a license to display the preprint in perpetuity.

It is made available under a CC-BY-NC-ND 4.0 International license .

410 cardiometabolic profile which can be observed as early as infancy [35]. A previous study

411 suggests that males who exhibit a high genetic risk for PCOS are more likely to present with

412 morbid obesity, T2D, and diabetes mellitus, two findings which were confirmed in this study [12].

413 Although we also found associations with CVD phenotypes in males, these were largely

414 influenced by genetically predicted BMI which can significantly increase the lifetime risk for CVD

415 and mortality rates of high-risk individuals [37]. Genetic susceptibility for PCOS could be an

416 additional catalyst for these events in males, making individuals already predisposed to adverse

417 metabolic outcomes more vulnerable.

In an effort to determine whether genetic risk for phenotypes comorbid with PCOS could

419 also increase risk for PCOS, we conducted separate multivariable logistic regressions with PRS

420 for BMI, diastolic blood pressure, systolic blood pressure, pulse pressure, T2D, heart failure,

421 and CAD on the PCOS diagnosis outcome and found no significant associations outside of

$422 \mathrm{~T}_{2} \mathrm{D}_{\mathrm{PRS}}$ and BMIPRS. This was unsurprising as the relationship between PCOS and CVD are still

423 poorly elucidated and often debated [38]. It is possible that CVD is more prevalent in genetically

424 high-risk males than females. The sex-difference in CVD prevalence may also be reflected in

425 the PRS which may fail to fully capture CVD genetic risk for PCOS when stratified by sex due to

426 fewer females in the discovery sample.

427 This study provides novel insight into PCOS genetic etiology and continues to

428 underscore the importance of BMI in PCOS risk. As with T2D, we found that genetically

429 predicted BMI is primarily responsible for the phenotypic association between T2D PRs and

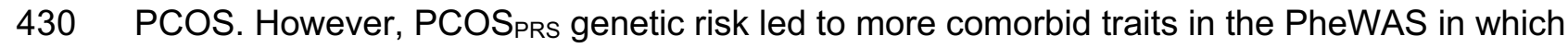

431 both environmental and genetically predicted BMI influenced the metabolic associations. This

432 may mean that PCOS patients with a family history of T2D can have an increased risk for

433 morbid outcomes, as females with PCOS are already more likely to develop T2D at an earlier

434 age [39]. This genetic susceptibility could also explain the high prevalence of insulin resistance

435 in PCOS patients, which can be as high as 70\% across all BMI strata [40]. These effects should 
436 be investigated further, as the genetic and biological pathways could differ in lean PCOS

437 patients who also experience a high rate of insulin resistance [41].

$438 \quad$ This study offers many strengths. Firstly, we showed that cardiometabolic associations

439 vary with sex and that the metabolic outcomes related to PCOS genetic architecture can be

440 further understood by studying both males and females. Secondly, we decomposed BMI into

441 genetically predicted (i.e., BMIPRS) and environmentally enriched (i.e., $\mathrm{BMI}_{\text {residual }}$ ) and evaluated

442 their respective roles in mediating the cardiometabolic profiles associated with PCOS PRS.

443 However, limitations include low power to detect any significant associations in our African

444 descent sample. To date, there is no PCOS GWAS of African descent individuals, limiting all

445 current similar studies to building PRS using European-based genetic variants, which do not

446 perform as well in non-European populations [11,12]. Second, we only examined one

447 environmental risk factor. Although many effects such as lifestyle and diet can be captured

448 through BMI, it is not an exhaustive measurement nor does it accurately account for the full

449 wellness of an individual $[42,43]$. Although other anthropometric features like hip-to-waist ratio

450 (WHR) may be better indicators of health for some phenotypes [44], this information is not

451 routinely collected in clinical settings or reported in EHRs. Furthermore, evidence does suggest

452 that clinically ascertained BMI may be more informative for PCOS than WHR [45]. Finally,

453 despite using the largest PCOS GWAS to date for this analysis, our PCOSPRS still only explains

454 a small portion of PCOS genetic variance. As these analyses expand, so too will our ability to

455 detect the full genetic spectrum of PCOS and its subphenotypes.

$456 \quad$ PCOS is a multifaceted disorder with genetic architecture that is reflective of its

457 heterogeneous outcomes. This polygenic structure captures a spectrum of metabolic

458 comorbidities that is even more apparent when compared between sexes. Our findings show

459 that males with high PCOS liability are indeed a high-risk group and those with a family history

460 of PCOS should be closely monitored for hypertension and CVD. This is also true for females

461 with PCOS and a family history of T2D, whose genetic risk could induce more severe comorbid 
medRxiv preprint doi: https://doi.org/10.1101/2021.10.23.21265391; this version posted October 26, 2021. The copyright holder for this preprint

(which was not certified by peer review) is the author/funder, who has granted medRxiv a license to display the preprint in perpetuity.

$$
\text { It is made available under a CC-BY-NC-ND } 4.0 \text { International license. }
$$

462 outcomes. As such, management and screening strategies should be updated to reflect

463 advances in PCOS etiology. This call to action is paramount and requires both widespread

464 dissemination of risk factor information to relevant stakeholders and increases in PCOS

465 research priorities and funding. This becomes even more crucial as PCOS comorbidities are

466 often under-recognized in clinical settings and metabolic conditions are underutilized in PCOS

467 screening methods [46-49]. 


\section{References}

1. Rotterdam ESHRE/ASRM-Sponsored PCOS consensus workshop group. Revised 2003 consensus on diagnostic criteria and long-term health risks related to polycystic ovary syndrome (PCOS). Hum Reprod. 2004;19: 41-47. doi:10.1093/humrep/deh098

2. Teede HJ, Misso ML, Costello MF, Dokras A, Laven J, Moran L, et al. Recommendations from the international evidence-based guideline for the assessment and management of polycystic ovary syndrome. Hum Reprod. 2018;33: 1602-1618. doi:10.1093/humrep/dey256

3. Shorakae S, Boyle J, Teede H. Polycystic ovary syndrome: a common hormonal condition with major metabolic sequelae that physicians should know about. Intern Med J. 2014;44: 720-726. doi:10.1111/imj.12495

4. Gibson-Helm M, Teede H, Dunaif A, Dokras A. Delayed Diagnosis and a Lack of Information Associated With Dissatisfaction in Women With Polycystic Ovary Syndrome. J Clin Endocrinol Metab. 2017;102: 604-612. doi:10.1210/jc.2016-2963

5. March WA, Moore VM, Willson KJ, Phillips DIW, Norman RJ, Davies MJ. The prevalence of polycystic ovary syndrome in a community sample assessed under contrasting diagnostic criteria. Human Reproduction. 2010;25: 544-551. doi:10.1093/humrep/dep399

6. Cussons AJ, Stuckey BGA, Walsh JP, Burke V, Norman RJ. Polycystic ovarian syndrome: marked differences between endocrinologists and gynaecologists in diagnosis and management. Clin Endocrinol. 2005;62: 289-295. doi:10.1111/j.1365-2265.2004.02208.x

7. Azziz R, Carmina E, Dewailly D, Diamanti-Kandarakis E, Escobar-Morreale HF, Futterweit W, et al. Criteria for Defining Polycystic Ovary Syndrome as a Predominantly Hyperandrogenic Syndrome: An Androgen Excess Society Guideline. The Journal of Clinical Endocrinology \& Metabolism. 2006;91: 4237-4245. doi:10.1210/jc.2006-0178

8. Sanchez-Garrido MA, Tena-Sempere M. Metabolic dysfunction in polycystic ovary syndrome: Pathogenic role of androgen excess and potential therapeutic strategies. Mol Metab. 2020;35: 100937. doi:10.1016/j.molmet.2020.01.001

9. Dapas M, Lin FTJ, Nadkarni GN, Sisk R, Legro RS, Urbanek M, et al. Distinct subtypes of polycystic ovary syndrome with novel genetic associations: An unsupervised, phenotypic clustering analysis. PLoS Med. 2020;17: e1003132. doi:10.1371/journal.pmed.1003132

10. Zhang Y, Movva VC, Williams MS, Lee MTM. Polycystic Ovary Syndrome Susceptibility Loci Inform Disease Etiological Heterogeneity. JCM. 2021;10: 2688. doi:10.3390/jcm10122688

11. Actkins KV, Singh K, Hucks D, Velez Edwards DR, Aldrich M, Cha J, et al. Characterizing the clinical and genetic spectrum of polycystic ovary syndrome in electronic health records. J Clin Endocrinol Metab. 2020. doi:10.1210/clinem/dgaa675

12. Joo YY, Actkins K, Pacheco JA, Basile AO, Carroll R, Crosslin DR, et al. A Polygenic and Phenotypic Risk Prediction for Polycystic Ovary Syndrome Evaluated by Phenome-Wide 
Association Studies. J Clin Endocrinol Metab. 2020;105: 1918-1936.

13. Lee H, Oh J-Y, Sung Y-A, Chung HW. A genetic risk score is associated with polycystic doi:10.1210/clinem/dgz326 ovary syndrome-related traits. Hum Reprod. 2016;31: 209-215.

doi:10.1093/humrep/dev282

512

513

514

515

516

517

518

519

520

521

522

523

524

525

526

527

528

529

530

531

532

533

534

535

536

537

538

539

540

541

542

543

544

14. Vink JM, Sadrzadeh S, Lambalk CB, Boomsma DI. Heritability of polycystic ovary syndrome in a Dutch twin-family study. J Clin Endocrinol Metab. 2006;91: 2100-2104. doi:10.1210/jc.2005-1494

15. Day FR, Hinds DA, Tung JY, Stolk L, Styrkarsdottir U, Saxena R, et al. Causal mechanisms and balancing selection inferred from genetic associations with polycystic ovary syndrome. Nat Commun. 2015;6: 8464. doi:10.1038/ncomms9464

16. Day F, Karaderi T, Jones MR, Meun C, He C, Drong A, et al. Large-scale genome-wide meta-analysis of polycystic ovary syndrome suggests shared genetic architecture for different diagnosis criteria. PLoS Genet. 2018;14: e1007813.

doi:10.1371/journal.pgen.1007813

17. Louwers YV, Lao O, Fauser BCJM, Kayser M, Laven JSE. The impact of self-reported ethnicity versus genetic ancestry on phenotypic characteristics of polycystic ovary syndrome (PCOS). J Clin Endocrinol Metab. 2014;99: E2107-16. doi:10.1210/jc.2014-1084

18. Bjonnes AC, Saxena R, Welt CK. Relationship between polycystic ovary syndrome and ancestry in European Americans. Fertil Steril. 2016;106: 1772-1777.

doi:10.1016/j.fertnstert.2016.08.033

19. Dapas M, Sisk R, Legro RS, Urbanek M, Dunaif A, Hayes MG. Family-based quantitative trait meta-analysis implicates rare noncoding variants in DENND1A in polycystic ovary syndrome. J Clin Endocrinol Metab. 2019. doi:10.1210/jc.2018-02496

20. Robinson JR, Wei W-Q, Roden DM, Denny JC. Defining Phenotypes from Clinical Data to Drive Genomic Research. Annu Rev Biomed Data Sci. 2018;1: 69-92.

doi:10.1146/annurev-biodatasci-080917-013335

21. Bien SA, Wojcik GL, Zubair N, Gignoux CR, Martin AR, Kocarnik JM, et al. Strategies for Enriching Variant Coverage in Candidate Disease Loci on a Multiethnic Genotyping Array. PLoS One. 2016;11: e0167758. doi:10.1371/journal.pone.0167758

22. Abraham G, Qiu Y, Inouye M. FlashPCA2: principal component analysis of Biobank-scale genotype datasets. Bioinformatics. 2017;33: 2776-2778. doi:10.1093/bioinformatics/btx299

23. Dennis JK, Sealock JM, Straub P, Lee YH, Hucks D, Actkins K, et al. Clinical laboratory test-wide association scan of polygenic scores identifies biomarkers of complex disease. Genome Med. 2021;13: 6. doi:10.1186/s13073-020-00820-8

24. Locke AE, Kahali B, Berndt SI, Justice AE, Pers TH, Day FR, et al. Genetic studies of body mass index yield new insights for obesity biology. Nature. 2015;518: 197-206.

doi:10.1038/nature14177 
25. Gaziano JM, Concato J, Brophy M, Fiore L, Pyarajan S, Breeling J, et al. Million Veteran Program: A mega-biobank to study genetic influences on health and disease. J Clin Epidemiol. 2016;70: 214-223. doi:10.1016/j.jclinepi.2015.09.016

26. Giri A, Hellwege JN, Keaton JM, Park J, Qiu C, Warren HR, et al. Trans-ethnic association study of blood pressure determinants in over 750,000 individuals. Nat Genet. 2019;51: 5162. doi:10.1038/s41588-018-0303-9

27. Vujkovic M, Keaton JM, Lynch JA, Miller DR, Zhou J, Tcheandjieu C, et al. Discovery of 318 new risk loci for type 2 diabetes and related vascular outcomes among 1.4 million participants in a multi-ancestry meta-analysis. Nat Genet. 2020;52: 680-691. doi:10.1038/s41588-020-0637-y

28. Shah S, Henry A, Roselli C, Lin H, Sveinbjörnsson G, Fatemifar G, et al. Genome-wide association and Mendelian randomisation analysis provide insights into the pathogenesis of heart failure. Nat Commun. 2020;11: 163. doi:10.1038/s41467-019-13690-5

29. Munz M, Richter GM, Loos BG, Jepsen S, Divaris K, Offenbacher S, et al. Genome-wide association meta-analysis of coronary artery disease and periodontitis reveals a novel shared risk locus. Sci Rep. 2018;8: 13678. doi:10.1038/s41598-018-31980-8

30. Ge T, Chen C-Y, Ni Y, Feng Y-CA, Smoller JW. Polygenic prediction via Bayesian regression and continuous shrinkage priors. Nat Commun. 2019;10: 1776. doi:10.1038/s41467-019-09718-5

31. Barber TM, Hanson P, Weickert MO, Franks S. Obesity and Polycystic Ovary Syndrome: Implications for Pathogenesis and Novel Management Strategies. Clin Med Insights Reprod Health. 2019;13: 1179558119874042. doi:10.1177/1179558119874042

32. Bulik-Sullivan B, Finucane HK, Anttila V, Gusev A, Day FR, Loh P-R, et al. An atlas of genetic correlations across human diseases and traits. Nat Genet. 2015;47: 1236-1241. doi:10.1038/ng.3406

33. Tingley D, Yamamoto T, Hirose K, Keele L, Imai K. Mediation: R package for causal mediation analysis. J Stat Softw. 2014. Available: https://oar.princeton.edu/jspui/handle/88435/pr1gj2f

34. Di Guardo F, Ciotta L, Monteleone M, Palumbo M. Male Equivalent Polycystic Ovarian Syndrome: Hormonal, Metabolic, and Clinical Aspects. Int J Fertil Steril. 2020;14: 79-83. doi:10.22074/ijfs.2020.6092

35. Recabarren SE, Smith R, Rios R, Maliqueo M, Echiburú B, Codner E, et al. Metabolic profile in sons of women with polycystic ovary syndrome. J Clin Endocrinol Metab. 2008;93: 1820-1826. doi:10.1210/jc.2007-2256

36. Subramaniam K, Tripathi A, Dabadghao P. Familial clustering of metabolic phenotype in brothers of women with polycystic ovary syndrome. Gynecol Endocrinol. 2019;35: 601603. doi:10.1080/09513590.2019.1566451 
medRxiv preprint doi: https://doi.org/10.1101/2021.10.23.21265391; this version posted October 26, 2021. The copyright holder for this preprint (which was not certified by peer review) is the author/funder, who has granted medRxiv a license to display the preprint in perpetuity. It is made available under a CC-BY-NC-ND 4.0 International license .

601

602

603

604

605

606

607

608

609

610

611

612

613

614

615

616

617

618

619

620

37. Khan SS, Ning H, Wilkins JT, Allen N, Carnethon M, Berry JD, et al. Association of Body Mass Index With Lifetime Risk of Cardiovascular Disease and Compression of Morbidity. JAMA Cardiol. 2018;3: 280-287. doi:10.1001/jamacardio.2018.0022

38. Papadakis G, Kandaraki E, Papalou O, Vryonidou A, Diamanti-Kandarakis E. Is cardiovascular risk in women with PCOS a real risk? Current insights. Minerva Endocrinol. 2017;42: 340-355. doi:10.23736/S0391-1977.17.02609-8

39. Rubin KH, Glintborg D, Nybo M, Abrahamsen B, Andersen M. Development and Risk Factors of Type 2 Diabetes in a Nationwide Population of Women With Polycystic Ovary Syndrome. J Clin Endocrinol Metab. 2017;102: 3848-3857. doi:10.1210/jc.2017-01354

40. Diamanti-Kandarakis E, Dunaif A. Insulin resistance and the polycystic ovary syndrome revisited: an update on mechanisms and implications. Endocr Rev. 2012;33: 981-1030. doi:10.1210/er.2011-1034

41. Escobar-Morreale HF. Polycystic ovary syndrome: definition, aetiology, diagnosis and treatment. Nat Rev Endocrinol. 2018;14: 270-284. doi:10.1038/nrendo.2018.24

42. Rothman KJ. BMI-related errors in the measurement of obesity. Int J Obes (Lond). 2008;32 Suppl 3: S56-59. doi:10.1038/ijo.2008.87

43. Chrysant SG, Chrysant GS. The single use of body mass index for the obesity paradox is misleading and should be used in conjunction with other obesity indices. Postgrad Med. 2019;131: 96-102. doi:10.1080/00325481.2019.1568019

44. Li C, Engström G, Hedblad B, Calling S, Berglund G, Janzon L. Sex differences in the relationships between BMI, WHR and incidence of cardiovascular disease: a populationbased cohort study. Int J Obes (Lond). 2006;30: 1775-1781. doi:10.1038/sj.ijo.0803339

45. Venkatesh SS, Ferreira T, Benonisdottir S, Rahmioglu N, Becker CM, Granne I, et al. The role of obesity in female reproductive conditions: A Mendelian Randomisation study. Genetic and Genomic Medicine; 2021 Jun. doi:10.1101/2021.06.01.21257781

46. Rodgers RJ, Avery JC, Moore VM, Davies MJ, Azziz R, Stener-Victorin E, et al. Complex diseases and co-morbidities: polycystic ovary syndrome and type 2 diabetes mellitus. Endocr Connect. 2019;8: R71-R75. doi:10.1530/EC-18-0502

47. Piltonen TT, Ruokojärvi M, Karro H, Kujanpää L, Morin-Papunen L, Tapanainen JS, et al. Awareness of polycystic ovary syndrome among obstetrician-gynecologists and endocrinologists in Northern Europe. PLOS ONE. 2019;14: e0226074. doi:10.1371/journal.pone.0226074

48. Dokras A, Saini S, Gibson-Helm M, Schulkin J, Cooney L, Teede H. Gaps in knowledge among physicians regarding diagnostic criteria and management of polycystic ovary syndrome. Fertil Steril. 2017;107: 1380-1386.e1. doi:10.1016/j.fertnstert.2017.04.011

49. Mott MM, Kitos NR, Coviello AD. Practice Patterns in Screening for Metabolic Disease in Women with PCOS of Diverse Race-Ethnic Backgrounds. Endocr Pract. 2014;20: 855863. doi:10.4158/EP13414.OR 
Table 1. Hypertension is Significantly Modified by Sex for PCOSPRs.

622

\begin{tabular}{|c|c|c|c|c|c|c|c|c|c|}
\hline Phenotype & Estimate & SE & Z-Value & $\mathbf{P}$ & OR & LCl & UCl & Cases & Controls \\
\hline Hypertension & -0.05 & 0.02 & -2.69 & $7.24 \mathrm{E}-03$ & 0.95 & 0.91 & 0.99 & 24,574 & 35,352 \\
\hline $\begin{array}{c}\text { Essential } \\
\text { hypertension }\end{array}$ & -0.05 & 0.02 & -2.66 & 7.71E-03 & 0.95 & 0.91 & 0.99 & 24,159 & 35,352 \\
\hline $\begin{array}{l}\text { Hypertensive heart } \\
\text { disease }\end{array}$ & -0.11 & 0.04 & -2.51 & 0.01 & 0.89 & 0.82 & 0.98 & 2,696 & 35,352 \\
\hline $\begin{array}{c}\text { Coronary } \\
\text { atherosclerosis }\end{array}$ & -0.04 & 0.03 & -1.46 & 0.14 & 0.96 & 0.91 & 1.01 & 9,123 & 49,700 \\
\hline $\begin{array}{c}\text { Ischemic Heart } \\
\text { Disease }\end{array}$ & -0.03 & 0.03 & -1.28 & 0.20 & 0.97 & 0.92 & 1.02 & 10,015 & 49,700 \\
\hline $\begin{array}{c}\text { Loss of teeth or } \\
\text { edentulism }\end{array}$ & -0.17 & 0.14 & -1.21 & 0.23 & 0.84 & 0.64 & 1.11 & 184 & 61,061 \\
\hline Obesity & 0.03 & 0.03 & 0.92 & 0.36 & 1.03 & 0.97 & 1.09 & 5,835 & 51,152 \\
\hline Type 2 diabetes & 0.02 & 0.02 & 0.90 & 0.37 & 1.02 & 0.97 & 1.07 & 8,990 & 51,286 \\
\hline Diabetes mellitus & 0.02 & 0.02 & 0.65 & 0.52 & 1.02 & 0.97 & 1.06 & 9,424 & 51,286 \\
\hline $\begin{array}{l}\text { Overweight, obesity } \\
\text { and other } \\
\text { hyperalimentation }\end{array}$ & 0.01 & 0.03 & 0.23 & 0.82 & 1.01 & 0.95 & 1.06 & 6,841 & 51,152 \\
\hline
\end{tabular}

624 We used a logistic regression model to test the interaction of effect between PCOS PRS and sex.

625 Models were adjusted for age, sex, genetic ancestry, and the interaction term. Estimate effects 626 are in the direction of females. 
medRxiv preprint doi: https://doi.org/10.1101/2021.10.23.21265391; this version posted October 26, 2021. The copyright holder for this preprint (which was not certified by peer review) is the author/funder, who has granted medRxiv a license to display the preprint in perpetuity.

It is made available under a CC-BY-NC-ND 4.0 International license.

Table 2. PCOS Shares Genetic Architecture with Cardiometabolic Traits

629

\begin{tabular}{c|c|c|c|c}
\hline Traits & Genetic Correlation & SE & Z & P \\
\hline Diastolic Blood Pressure & $-3.60 \%$ & 0.07 & -0.54 & 0.59 \\
\hline Systolic Blood Pressure & $9.33 \%$ & 0.05 & 1.79 & 0.07 \\
\hline Pulse Pressure & $13.46 \%$ & 0.05 & 2.54 & 0.01 \\
\hline Type 2 Diabetes & $29.26 \%$ & 0.05 & 5.92 & $3.25 \mathrm{e}-09$ \\
\hline Heart Failure & $26.51 \%$ & 0.09 & 3.02 & 0.003 \\
\hline Coronary Artery Diseases & $17.35 \%$ & 0.09 & 1.95 & 0.05 \\
\hline Body Mass Index & $43.32 \%$ & 0.05 & 8.85 & $8.77 \mathrm{e}-19$ \\
\hline
\end{tabular}

630

631 
632

633

634

635

636

637
Table 3. BMI Genetic Variance is a Causal Risk Factor for PCOS and T2D

\begin{tabular}{|c|c|c|c|c|c|}
\hline Exposure & Mediator & Outcome & $\begin{array}{c}\text { ADE } \\
\beta(95 \% \mathrm{Cl})\end{array}$ & $\begin{array}{c}\text { ACME } \\
\beta(95 \% \mathrm{Cl})\end{array}$ & $\begin{array}{c}\text { Proportion Mediated } \\
(95 \% \mathrm{Cl})\end{array}$ \\
\hline \multirow{2}{*}{$B M I_{P R S}$} & PCOS & T2D & $\begin{array}{c}0.025 \\
(0.014-0.037) \\
P=<2 e-16\end{array}$ & $\begin{array}{c}0.002 \\
(6.92 \mathrm{E}-04-0.004) \\
P=<2 e-16\end{array}$ & $\begin{array}{c}0.071 \\
(0.025-0.144) \\
P=<2 e-16\end{array}$ \\
\hline & T2D & PCOS & $\begin{array}{c}0.025 \\
(0.013-0.037) \\
P=<2 e-16 \\
\end{array}$ & $\begin{array}{c}0.002 \\
(0.001-0.004) \\
P=<2 e-16\end{array}$ & $\begin{array}{c}0.090 \\
(0.039-0.191) \\
P=<2 e-16\end{array}$ \\
\hline \multirow{2}{*}{$B M I_{\text {residual }}$} & PCOS & $\mathrm{T} 2 \mathrm{D}$ & $\begin{array}{c}0.037 \\
(0.023-0.052) \\
P=<2 e-16\end{array}$ & $\begin{array}{c}0.006 \\
(0.002-0.010) \\
P=<2 e-16\end{array}$ & $\begin{array}{c}0.136 \\
(0.049-0.254) \\
P=<2 e-16\end{array}$ \\
\hline & T2D & PCOS & $\begin{array}{c}0.127 \\
(0.104-0.150) \\
P=<2 e-16\end{array}$ & $\begin{array}{c}0.003 \\
(8.12-04-0.005) \\
P=0.004\end{array}$ & $\begin{array}{c}0.021 \\
(0.006-0.042) \\
P=0.004\end{array}$ \\
\hline
\end{tabular}

$\mathrm{ADE}=$ average direct effect, $\mathrm{ACME}=$ average causal mediation effect, $\mathrm{Cl}=$ confidence interval 
640

641
Table 4. Genetic effects of T2D Contributes to Environmental BMI.

\begin{tabular}{|c|c|c|c|c|c|c|}
\hline Sex & Exposure & Mediator & Outcome & $\begin{array}{c}\text { ADE } \\
\beta(95 \% \mathrm{Cl})\end{array}$ & $\begin{array}{c}\text { ACME } \\
\beta(95 \% \mathrm{CI})\end{array}$ & $\begin{array}{l}\text { Proportion } \\
\text { Mediated } \\
(95 \% \mathrm{Cl})\end{array}$ \\
\hline $\begin{array}{c}\text { Sex- } \\
\text { Combined }\end{array}$ & \multirow{3}{*}{$\mathrm{PCOS}_{\mathrm{PRS}}$} & \multirow{3}{*}{$\mathrm{T} 2 \mathrm{D}$} & \multirow{3}{*}{$B M I_{\text {residual }}$} & $\begin{array}{c}0.041 \\
(-0.055-0.147) \\
P=0.44\end{array}$ & $\begin{array}{c}0.059 \\
(0,033-0.088) \\
P=<2 e-16\end{array}$ & $\begin{array}{c}0.589 \\
(-1.112-3.248) \\
P=0.06\end{array}$ \\
\hline Females & & & & $\begin{array}{c}0.024 \\
(-0.102-0.172) \\
P=0.78\end{array}$ & $\begin{array}{c}0.059 \\
(0.041-0.121) \\
P=<2 e-16\end{array}$ & $\begin{array}{c}0.652 \\
(-4.638-6.128) \\
P=0.18\end{array}$ \\
\hline Males & & & & $\begin{array}{c}0.040 \\
(-0.101-0.176) \\
P=0.58\end{array}$ & $\begin{array}{c}0.038 \\
(0.004-0.074) \\
P=0.02\end{array}$ & $\begin{array}{c}0.342 \\
(-2.354-4.320) \\
P=0.31\end{array}$ \\
\hline Females & T2 $D_{\text {PRS }}$ & PCOS & $\mathrm{BMI}_{\text {residual }}$ & $\begin{array}{c}0.268 \\
(0.018-0.519) \\
P=0.04\end{array}$ & $\begin{array}{c}0.139 \\
(0.046-0.242) \\
P=0.002\end{array}$ & $\begin{array}{c}0.338 \\
(0.122-0.863) \\
P=0.004\end{array}$ \\
\hline
\end{tabular}


Table 5. Genetically Regulated BMI is a Stronger Mediator in PCOS $_{\mathrm{PRS}}$ Shared Metabolic Pathways.

\begin{tabular}{|c|c|c|c|c|c|}
\hline Sex & Mediator & Outcome & $\begin{array}{c}\text { ADE } \\
\beta(95 \% \mathrm{Cl})\end{array}$ & $\begin{array}{c}\text { ACME } \\
\beta(95 \% \mathrm{Cl})\end{array}$ & $\begin{array}{l}\text { Proportion } \\
\text { Mediated } \\
(95 \% \mathrm{Cl})\end{array}$ \\
\hline \multirow{6}{*}{$\begin{array}{c}\text { Sex- } \\
\text { Combined }\end{array}$} & BMI & \multirow{2}{*}{ T2D } & $\begin{array}{c}0.009 \\
(0.004-0.014) \\
P=<2 e-16\end{array}$ & $\begin{array}{c}0.005 \\
(0.004-0.007) \\
P=<2 e-16\end{array}$ & $\begin{array}{c}0.367 \\
(0.250-0.585) \\
P=<2 e-16\end{array}$ \\
\hline & $\begin{array}{c}\text { BMI } \\
\text { Residuals }\end{array}$ & & $\begin{array}{c}0.0134 \\
(0.008-0.019) \\
P=<2 e-16\end{array}$ & $\begin{array}{c}0.001 \\
(-1.76 \mathrm{E}-04-0.002) \\
P=0.09\end{array}$ & $\begin{array}{c}0.072 \\
(-0.011-0.155) \\
P=0.09\end{array}$ \\
\hline & BMI & \multirow{2}{*}{ Hypertension } & $\begin{array}{c}0.007 \\
(-2.13 \mathrm{e}-04-0.013) \\
P=0.062\end{array}$ & $\begin{array}{c}0.005 \\
(0.004-0.006) \\
P=<2 e-16\end{array}$ & $\begin{array}{c}0.435 \\
(0.269-1.043) \\
P=<2 e-16\end{array}$ \\
\hline & $\begin{array}{c}\text { BMI } \\
\text { Residuals }\end{array}$ & & $\begin{array}{c}0.012 \\
(0.005-0.0178) \\
P=0.002\end{array}$ & $\begin{array}{c}8.89 \mathrm{e}-04 \\
(-3.13 \mathrm{E}-04-0.002) \\
P=0.13\end{array}$ & $\begin{array}{c}0.072 \\
(-0.036-0.207) \\
P=0.13\end{array}$ \\
\hline & BMI & \multirow{2}{*}{$\begin{array}{l}\text { Hypertensive } \\
\text { Heart Disease }\end{array}$} & $\begin{array}{c}0.008 \\
(0.003-0.013) \\
P=0.006\end{array}$ & $\begin{array}{c}0.002 \\
(0.001-0.003) \\
P=<2 e-16\end{array}$ & $\begin{array}{c}0.237 \\
(0.144-0.457) \\
P=0.002\end{array}$ \\
\hline & $\begin{array}{c}\text { BMI } \\
\text { Residuals }\end{array}$ & & $\begin{array}{c}0.009 \\
(0.004-0.014) \\
P=0.002 \\
\end{array}$ & $\begin{array}{c}0.0006 \\
(-0.0001-0.001) \\
P=0.09\end{array}$ & $\begin{array}{c}0.062 \\
(-0.011-0.152) \\
P=0.09\end{array}$ \\
\hline \multirow{3}{*}{ Females } & BMI & \multirow{2}{*}{ T2D } & $\begin{array}{c}0.012 \\
(0.005-0.019) \\
P=<2 e-16\end{array}$ & $\begin{array}{c}0.005 \\
(0.004-0.007) \\
P=<2 e-16\end{array}$ & $\begin{array}{c}0.315 \\
(0.208-0.535) \\
P=<2 e-16\end{array}$ \\
\hline & $\begin{array}{c}\text { BMI } \\
\text { Residuals }\end{array}$ & & $\begin{array}{c}0.016 \\
(0.009-0.023) \\
P=<2 e-16\end{array}$ & $\begin{array}{c}9.64 \mathrm{e}-04 \\
(-6.00 \mathrm{e}-04-0.003) \\
P=0.22\end{array}$ & $\begin{array}{c}0.058 \\
(-0.037-0.154) \\
P=0.22\end{array}$ \\
\hline & BMI & Hypertension & $\begin{array}{c}0.002 \\
(-0.007-0.010) \\
P=0.73\end{array}$ & $\begin{array}{c}0.006 \\
(0.004-0.007) \\
P=<2 e-16\end{array}$ & $\begin{array}{c}0.742 \\
(-2.165-5.363) \\
P=0.08\end{array}$ \\
\hline
\end{tabular}




\begin{tabular}{|c|c|c|c|c|c|}
\hline & $\begin{array}{c}\text { BMI } \\
\text { Residuals }\end{array}$ & & $\begin{array}{c}0.007 \\
(-0.002-0.015) \\
P=0.11\end{array}$ & $\begin{array}{c}9.01 \mathrm{e}-04 \\
(-7.86 \mathrm{E}-04-0.002) \\
P=0.26\end{array}$ & $\begin{array}{c}0.112 \\
(-0.426-0.806) \\
P=0.30\end{array}$ \\
\hline & $\mathrm{BMI}$ & \multirow{2}{*}{$\begin{array}{l}\text { Hypertensive } \\
\text { Heart Disease }\end{array}$} & $\begin{array}{c}0.003 \\
(-0.002-0.009) \\
P=0.31\end{array}$ & $\begin{array}{c}0.002 \\
(0.001-0.003) \\
P=<2 \mathrm{e}-16\end{array}$ & $\begin{array}{c}0.378 \\
(-1.602-3.278) \\
P=0.082\end{array}$ \\
\hline & $\begin{array}{c}\text { BMI } \\
\text { Residuals }\end{array}$ & & $\begin{array}{c}0.005 \\
(-9.79 e-04-0.011) \\
P=0.11\end{array}$ & $\begin{array}{c}5.50 \mathrm{e}-04 \\
(-0.0002-0.001) \\
P=0.14\end{array}$ & $\begin{array}{c}0.097 \\
(-0.367-0.781) \\
P=0.20\end{array}$ \\
\hline \multirow{6}{*}{ Males } & $\mathrm{BMI}$ & \multirow{2}{*}{ T2D } & $\begin{array}{c}0.007 \\
(-0.002-0.016) \\
P=0.13\end{array}$ & $\begin{array}{c}0.005 \\
(0.003-0.007) \\
P=<2 e-16\end{array}$ & $\begin{array}{c}0.430 \\
(0.186-1.377) \\
P=0.02\end{array}$ \\
\hline & $\begin{array}{c}\text { BMI } \\
\text { Residuals }\end{array}$ & & $\begin{array}{c}0.011 \\
(0.001-0.020) \\
P=0.03\end{array}$ & $\begin{array}{c}0.001 \\
(-8.26 \mathrm{e}-04-0.003) \\
P=0.27\end{array}$ & $\begin{array}{c}0.086 \\
(-0.115-0.421) \\
P=0.28\end{array}$ \\
\hline & $\mathrm{BMI}$ & Hynortencion & $\begin{array}{c}0.014 \\
(0.004-0.024) \\
P=0.006\end{array}$ & $\begin{array}{c}0.004 \\
(0.003-0.006) \\
P=<2 e-16\end{array}$ & $\begin{array}{c}0.237 \\
(0.127-0.530) \\
P=0.002\end{array}$ \\
\hline & $\begin{array}{c}\text { BMI } \\
\text { Residuals }\end{array}$ & Hypertension & $\begin{array}{c}0.018 \\
(0.009-0.027) \\
P=<2 e-16\end{array}$ & $\begin{array}{c}8.65 \mathrm{e}-04 \\
(-8.84 \mathrm{e}-04-0.003) \\
P=0.30\end{array}$ & $\begin{array}{c}0.046 \\
(-0.049-0.156) \\
P=0.30\end{array}$ \\
\hline & $\mathrm{BMI}$ & Hypertensive & $\begin{array}{c}0.015 \\
(0.006-0.025) \\
P=<2 \mathrm{e}-16\end{array}$ & $\begin{array}{c}0.003 \\
(0.001-0.004) \\
P=<2 \mathrm{e}-16\end{array}$ & $\begin{array}{c}0.148 \\
(0.059-0.349) \\
P=<2 \mathrm{e}-16\end{array}$ \\
\hline & $\begin{array}{c}\text { BMI } \\
\text { Residuals }\end{array}$ & Heart Disease & $\begin{array}{c}0.017 \\
(0.008-0.027) \\
P=<2 e-16\end{array}$ & $\begin{array}{c}0.0006 \\
(-8.82 e-04-0.002) \\
P=0.43\end{array}$ & $\begin{array}{c}0.034 \\
(-0.063-0.139) \\
P=0.43\end{array}$ \\
\hline
\end{tabular}

PCOS PRs was analyzed as the exposure variable. $\mathrm{P}<0.05$ was considered statistically significant. ADE $=$ average direct effect, $\mathrm{ACME}=$ average causal mediation effect, $\mathrm{Cl}=$ confidence interval 
A.

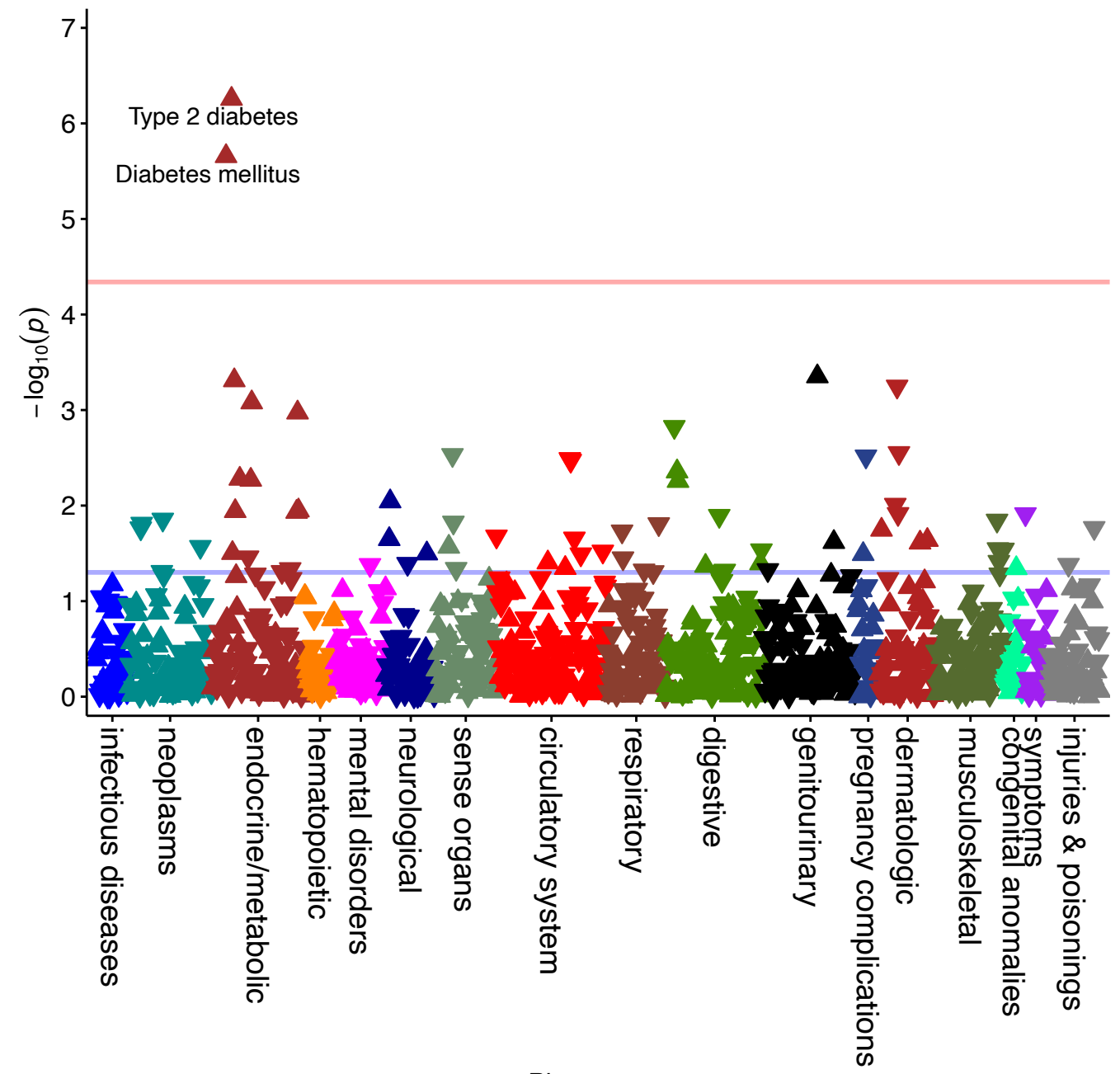

B.

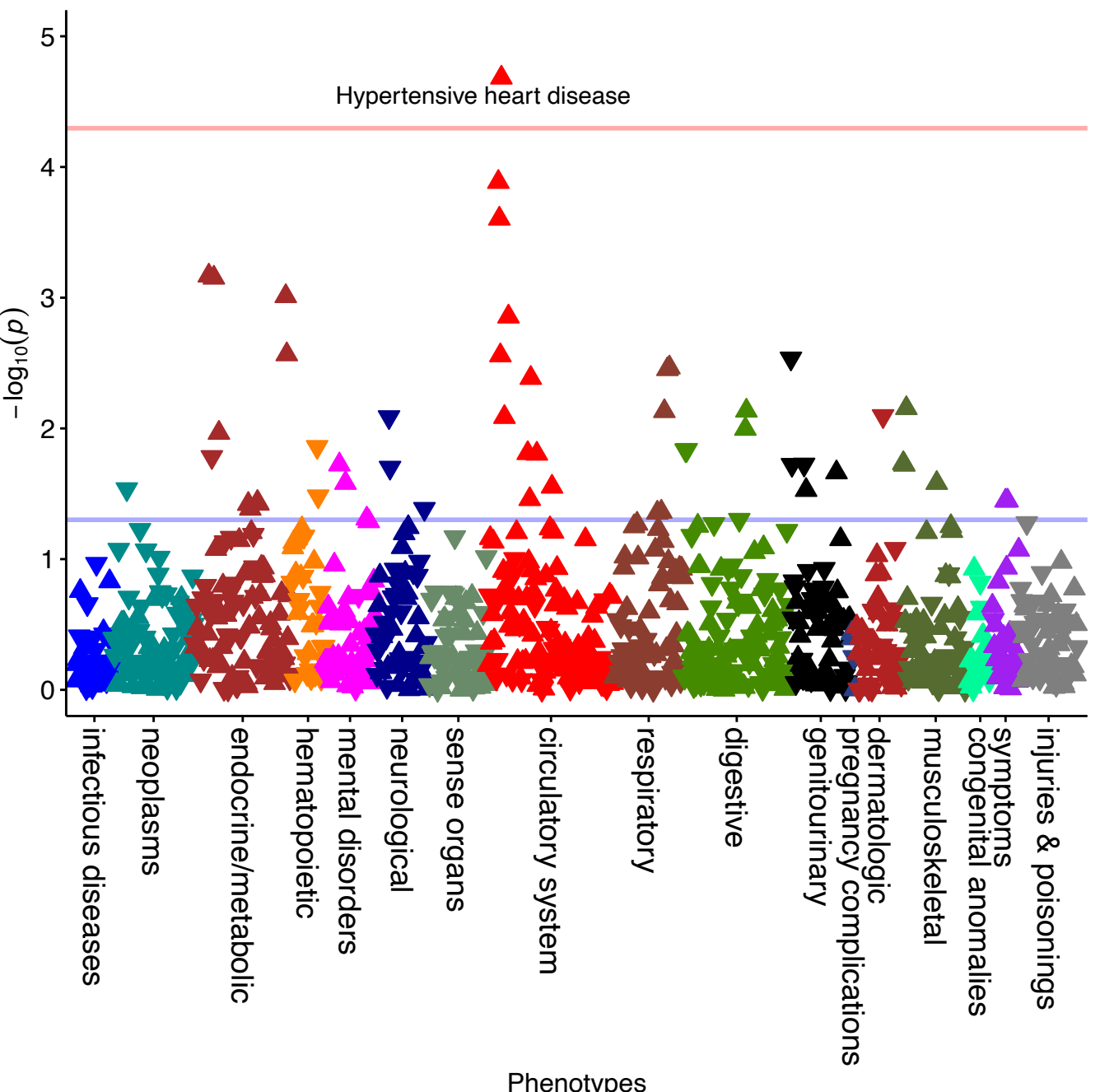

650 Figure 1. Metabolic Associations Vary by Sex for Genetically High-Risk Individuals. PCOS PRs phenome-wide association study 651 results are displayed in the Manhattan plots for (A) females and (B) males. The red line represents the Bonferroni correction of $P=$

$6524.56 \mathrm{e}-05$ and $\mathrm{P}=5.07 \mathrm{e}-05$, respectively. Arrows in the upward direction represent increased risk. 


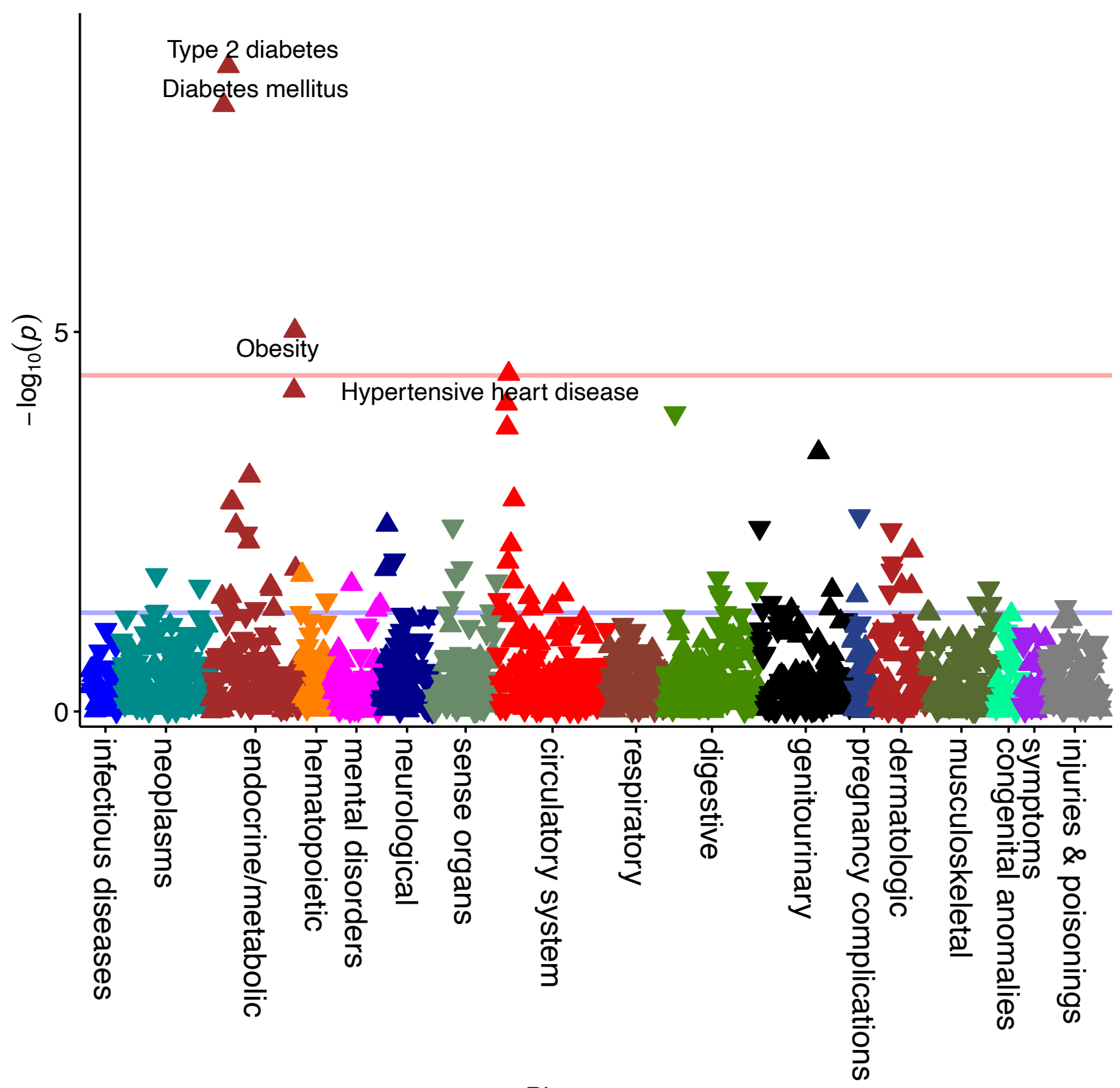


A.

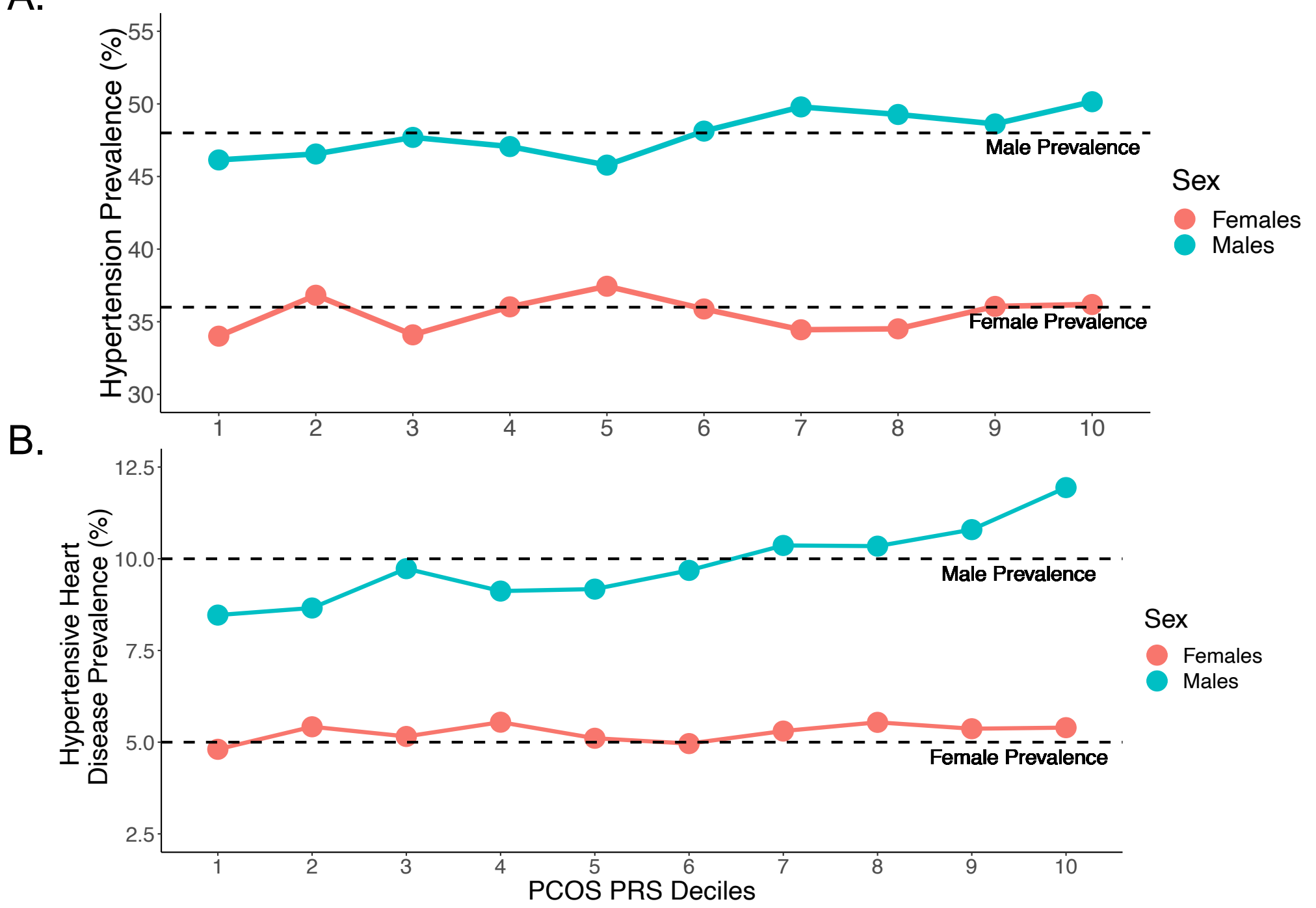

662

663

664

665

666

667

668

669
Figure 3. The Prevalence of Hypertensive Metabolic Traits Differs Across the PCOS PRS Strata. (A) Top Figure: Hypertension, (B) Bottom Figure: Hypertensive Heart Disease. The prevalence of the significant phenotypes from the sex interaction analysis are shown. The prevalence for hypertension in our dataset was $48 \%$ for males and $36 \%$ for females. The prevalence for hypertensive heart disease was $10 \%$ for males and $5 \%$ for females. 


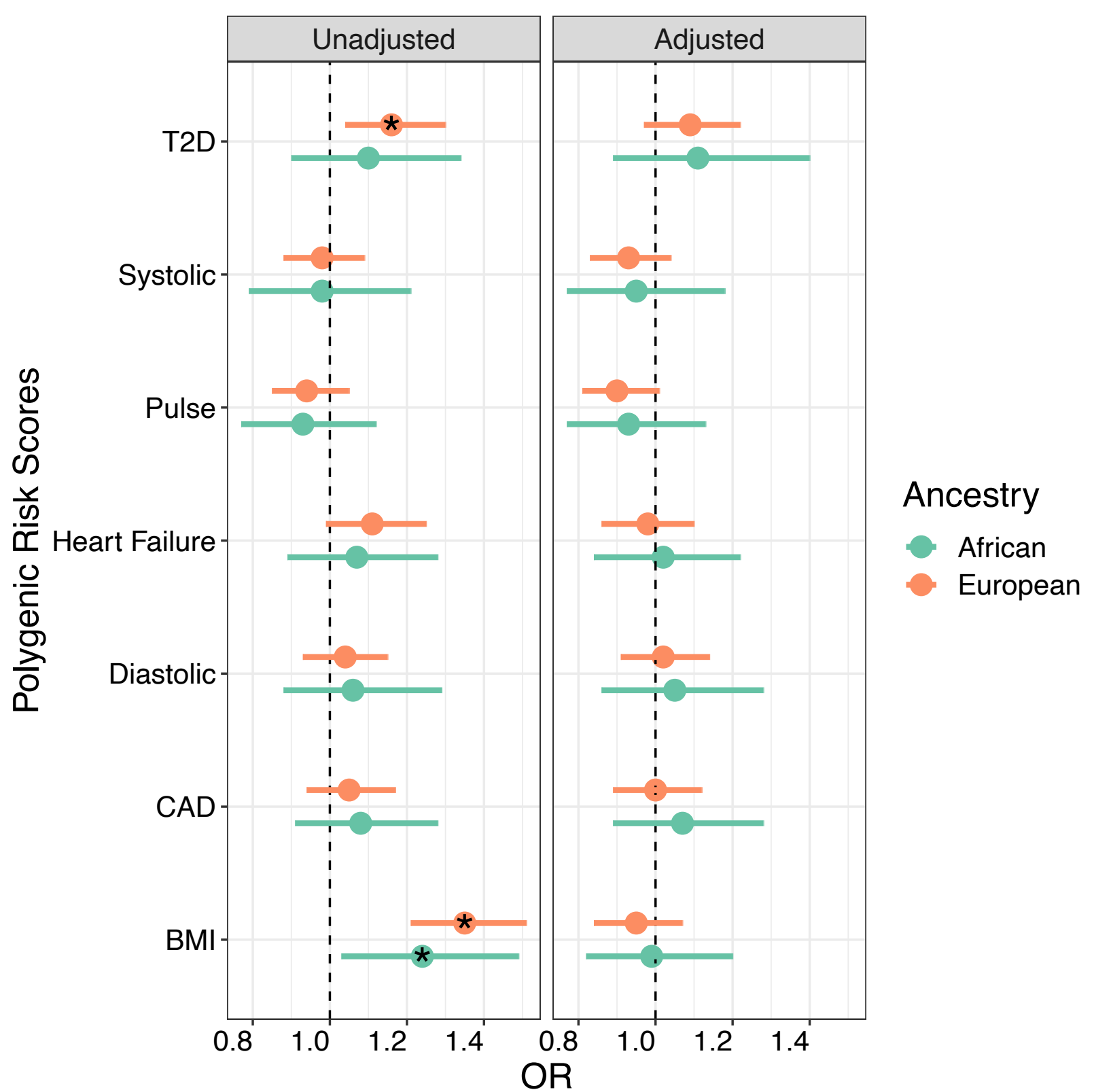

Figure 4. T2D $D_{P R S}$ and $B M I_{P R S}$ are Associated with PCOS Case Status. The results from the logistic regression analysis between PCOS diagnosis and polygenic risk scores (PRS) generated for significant metabolic traits from the PheWAS analysis are displayed in the forest plot. One model was unadjusted for body mass index (unadjusted) and the other model was adjusted for body mass index (adjusted). * indicates $\mathrm{P}<0.05$ 
medRxiv preprint doi: https://doi.org/10.1101/2021.10.23.21265391; this version posted October 26, 2021. The copyright holder for this preprint (which was not certified by peer review) is the author/funder, who has granted medRxiv a license to display the preprint in perpetuity. It is made available under a CC-BY-NC-ND 4.0 International license.

681

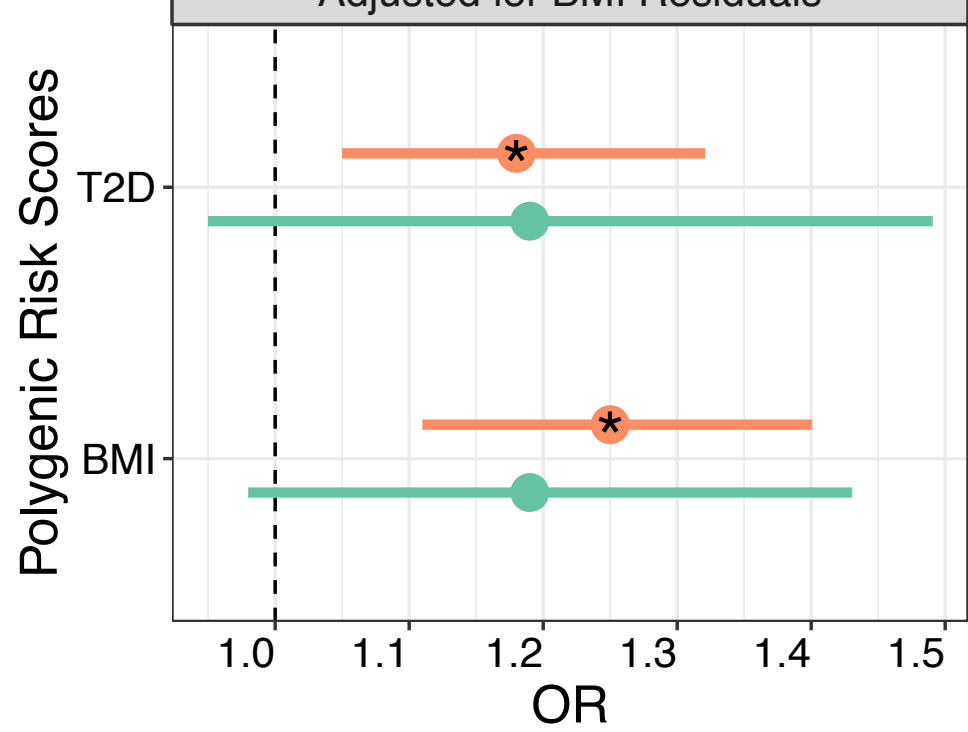

\section{Ancestry \\ African \\ European}

Figure 5. T2 $D_{P R S}$ is Associated with PCOS After Accounting for BMI residual. The logistic regression model between $\mathrm{T}_{2} \mathrm{D}_{\mathrm{PRS}}$ and $\mathrm{PCOS}$ diagnosis was covaried for age, the top ten principal components for ancestry, and $\mathrm{BMI}_{\text {residual. }} \mathrm{BMI}_{\text {residual }}$ represents $\mathrm{BMI}$ after the removal of BMI genetic variance from the variable. * indicates $\mathrm{P}<0.05$ 